\title{
Precarious status of the Endangered dhole Cuon alpinus in the high elevation Eastern Himalayan habitats of Khangchendzonga Biosphere Reserve, Sikkim, India
}

\author{
Taweir Bashir, Tapajit Bhattacharya, Kamal Poudyal, Manjari Roy \\ and S A MB ANDAM S ATHYAKUMAR
}

\begin{abstract}
During 2008-2010 we investigated the ecology of the Endangered dhole or wild dog Cuon alpinus in Khangchendzonga Biosphere Reserve in the Eastern Himalaya in Sikkim, India. We conducted camera trapping ( $\mathrm{n}=71$ sites, 6,278 camera-days) and sign surveying along trails $(n=24 ; 629.43 \mathrm{~km}$ of effort) to assess the relative abundance, distribution and activity pattern of the dhole. Morphological characteristics evident in the 61 camera-trap photographs indicate that the dhole population in the Reserve may be the rare and genetically distinct subspecies C. alpinus primaevus. We detected dholes over a wide elevation range (2,501-4,100 $\mathrm{m}$ ) that encompassed the upper temperate, subalpine, and alpine scrub zones. Dholes were diurnal, with peak activity at 08.00-10.00. Analysis of 41 scats indicated a diet comprising mainly mountain ungulates, rodents and pikas Ochotona sp. Although the frequency of occurrence of rodents was highest $(32 \%)$ in the scats, $98.7 \%$ of the total biomass consumed was of mountain ungulates. Historical reports (1888-1894) indicated that the dhole was formerly abundant in Sikkim but was hunted to meet the high demand for its alleged medicinal properties. With no information on the status of the dhole in Sikkim for over a century, our study suggests that the species is now rare in the Reserve. To aid the conservation of the dhole and its main ungulate prey species extensive research and monitoring are required in the Reserve and elsewhere in the Eastern Himalaya.
\end{abstract}

Keywords Cuon alpinus primaevus, dhole, diet, Eastern Himalaya, India, mountain ungulates, Sikkim, subalpine forest

\section{Introduction}

he Asiatic wild dog or dhole Cuon alpinus is a primarily

TaWlir Bashir, Tapajt Bhattacharya, Kamal Poudyal, Manjari Roy and SAMBANDAM SATHYAKUMAR (Corresponding author) Wildlife Institute of India, P.O. Box 18, Chandrabani, Dehradun 248 001, Uttarakhand, India. E-mail ssk@ wii.gov.in

Received 25 August 2011. Revision requested 20 March 2012.

Accepted 26 March 2012. First published online 15 October 2013. weighing $12-20 \mathrm{~kg}$, usually with a reddish or brown coat and a darker bushy tail (Johnsingh, 1985; Durbin et al., 2004). It is the only species in the genus Cuon, with 11 subspecies (Durbin et al., 2004; Iyengar et al., 2005), of which five are reported from south Asia (Johnsingh, 1985; Durbin et al., 2004). In some areas it was customarily and incorrectly categorized as vermin and assumed to reduce natural populations of wild ungulates and livestock. Organized reward hunting and poisoning exterminated the species over much of its range (Davidar, 1975). Recently, habitat degradation, extinction of prey populations, and conflicts with and persecution by humans has led to a marked reduction in the dhole's range (Iyengar et al., 2005), and it is categorized as Endangered on the IUCN Red List (Durbin et al., 2008).

Little is known of the dhole in north-east India and north of the river Ganges, and only a few short-term surveys have been carried out (Johnsingh, 1985; Stewart, 1993, 1994). In this area the species has been recorded in the states of Arunachal Pradesh, Assam, Meghalaya, West Bengal (Durbin et al., 2008) and Sikkim (Sathyakumar et al., 2011). Dhole-livestock conflict has been studied in Bhutan (Johnsingh et al., 2007), and the species' ecology is being studied in Pakke Tiger Reserve (Gopi et al., 2010). The presence of two subspecies of dhole was reported in Sikkim in the 19th century (Gammie, 1894). Jerdon (1874) and Blanford (1891) mentioned one species of dhole Cuon dukhunensis in Sikkim but that local people believed there were two, differing in colour, size and habits. These were a large type, brownish, with a black muzzle, occurring only in pairs or in groups of three or four, and a small type, reddish in colour, occurring in packs of 10-12 and hunting prey such as wild pig Sus scrofa, barking deer Muntiacus muntjak, goat Capra aegagrus and other livestock. The large type was believed to have medicinal properties and was hunted to meet this demand.

Here we present the first information in c. 100 years on the dhole in the high elevation habitats of Khangchendzonga Biosphere Reserve. Based on cameratrap photographs we present information on the species' morphology, activity patterns and distribution, and using scat analysis we investigate the dhole's diet. We also highlight the need for further research on the species and for appropriate protection to safeguard this particular subspecies. 


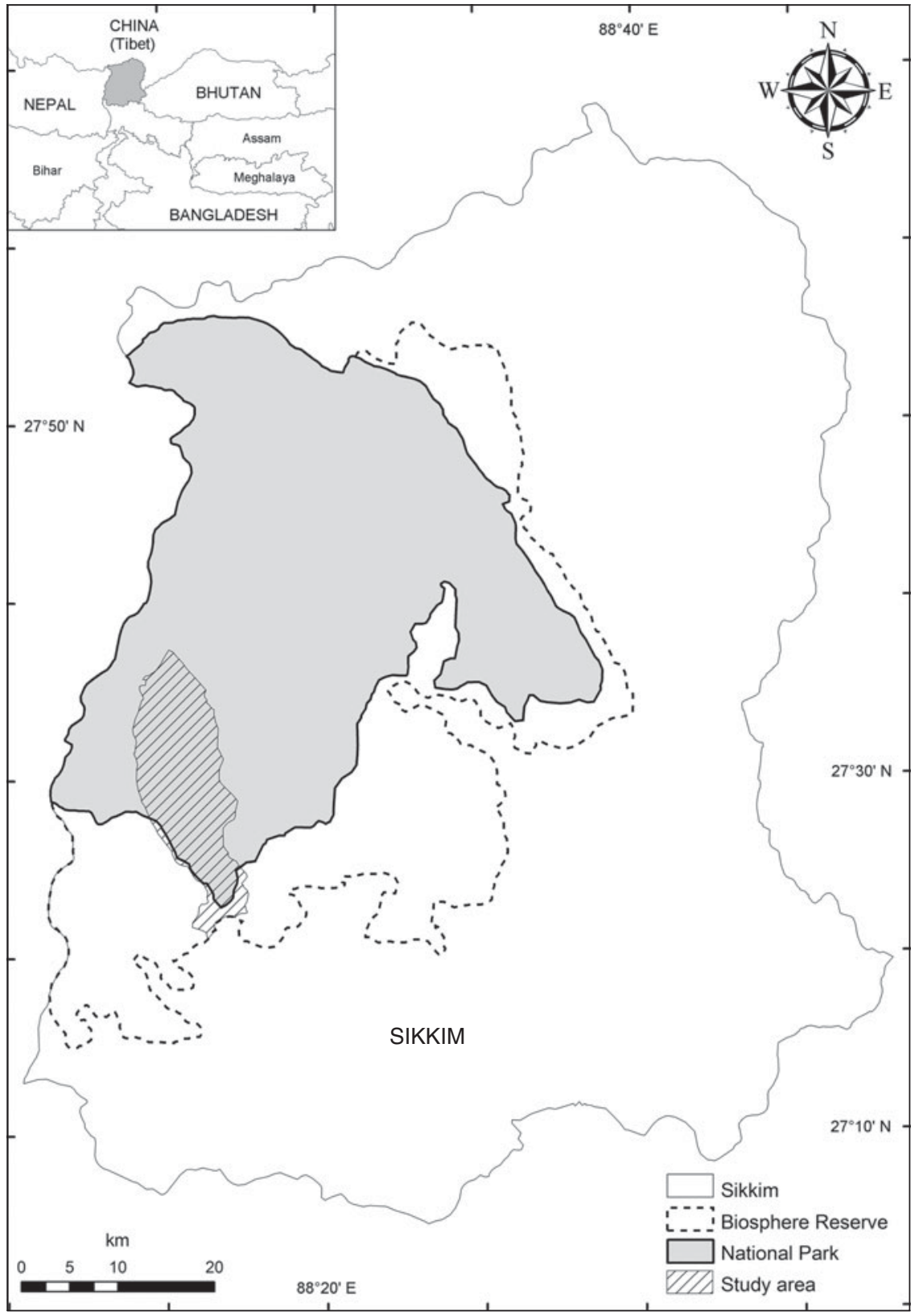

FIG. 1 Location of Khangchendzonga Biosphere Reserve in Sikkim, showing the Khangchendzonga National Park and the catchment of Prek Chu, in which we conducted this study. The shaded area on the inset indicates the location of Sikkim in north-east India.
Study area

Sikkim, a small mountainous state of India, is the westernmost part of the Eastern Himalayan biodiversity hotspot (Myers et al., 2000). This study was carried out in Khangchendzonga National Park and Biosphere Reserve (Fig. 1) from February 2008 to August 2010. The Reserve encompasses temperate, subalpine and alpine habitats $(1,220-5,000 \mathrm{~m})$ and rocky slopes, glacial moraines and permafrost zones $(>5,000-8,586 \mathrm{~m})$. There are seven water catchments, of which Prek Chu was selected as the study area as it contains all of the habitat types occurring in the Reserve (Sathyakumar et al., 2011). The $182 \mathrm{~km}^{2}$ of Prek Chu lies over 1,220 to $6,691 \mathrm{~m}$ and receives a total annual rainfall of 1,750-2,250 $\mathrm{mm}$ (Tambe, 2007). The major habitats and their percentage of the total area (Fig. 2) are mixed subtropical and mixed temperate (17\%), subalpine and krummholtz (36\%), alpine pastures (5\%), rock and snow cover $(41 \%)$ and water bodies $(1 \%)$.

\section{Methodology}

\section{Camera trapping}

Prek Chu was divided into $4 \mathrm{~km}^{2}$ blocks, using ArcGIS v. 9.0 (ESRI, Redlands, USA), and categorized into three survey zones according to habitat: temperate $(1,200-3,000 \mathrm{~m})$, subalpine $(3,000-4,000 \mathrm{~m})$ and alpine $(>4,000 \mathrm{~m})$. There were seven, 12 and five blocks in the temperate, subalpine and 


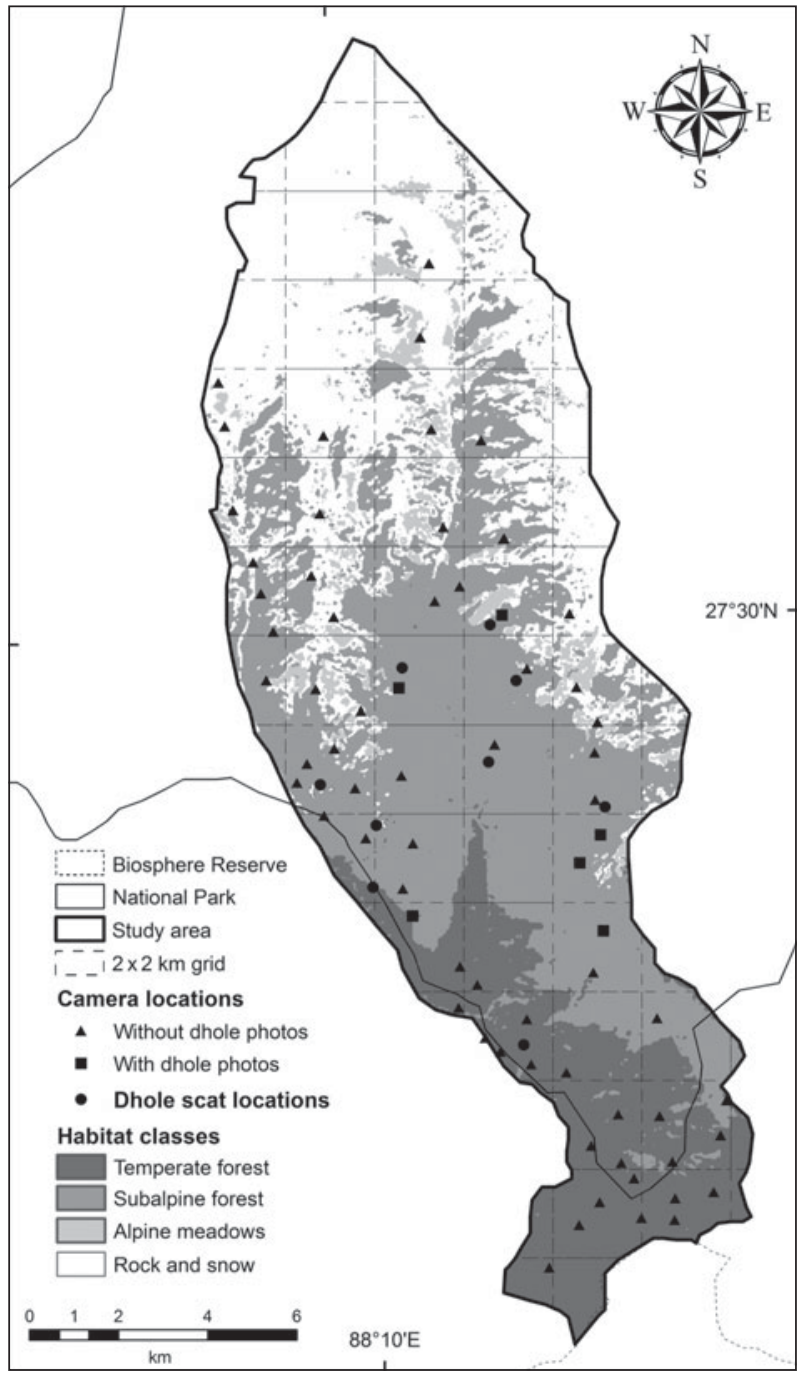

FIG. 2 The study area, Prek Chu catchment (Fig. 1), showing the locations of camera traps in a $2 \times 2 \mathrm{~km}$ grid and the locations where dhole Cuon alpinus scats were found.

alpine zones, respectively. The number of camera traps deployed corresponded to the area of the three zones and their accessibility, with a total of 27 camera traps deployed at 71 sites $(24,27$ and 20 in the temperate, subalpine and alpine zones, respectively; Fig. 2) for at least 30 days. We used four models of infrared-triggered camera units: two DeerCam (Non Typical, Inc., Park Falls, USA), two Wildview (Stealth Cam, LLC, Grand Prairie, USA), 18 Stealth Cam (Stealth Cam, LLC, Grand Prairie, USA) and five Moultrie (Moultrie Feeders, Alabaster, USA). As we were focusing on a rare species over a large area our strategy was to survey more trap sites less intensively rather than fewer trap sites more intensively (Mackenzie \& Royle, 2005). All cameras were set with a 1 minute delay between photographs and $24 \mathrm{~h}$ operation, and in four-picture burst mode.

Camera units were attached to trees $15-30 \mathrm{~cm}$ above the ground and 3-5 $\mathrm{m}$ from a trail or location where animal movement could be expected. Geographical coordinates, elevation and forest type were recorded at each cameratrap location. Camera traps were monitored at least twice per month, when batteries and memory cards were changed.

\section{Sign surveys}

Repeated surveys for dhole signs were carried out along 24 trails (with lengths of $1.5-7 \mathrm{~km}$ ). We walked six trails (a total of 67 trail walks, with a total of $201.15 \mathrm{~km}$ of effort) in the temperate zone, 12 trails (108 walks, $299.11 \mathrm{~km}$ ) in the subalpine zone and six trails (48 walks, $129.17 \mathrm{~km}$ ) in the alpine zone.

\section{Scat identification, collection and analysis}

Identification of dhole scat was straightforward as dholes tend to defecate in the middle of trails, unlike large felids, which defecate along the edges of trails, and because the members of a pack of dholes defecate in the same spot (Kumaraguru et al., 2011). Dhole scats were found in clusters, exposed on soil (Plate 1a), and could be distinguished easily from the scats of felids, which were stickier and deposited on grass (Johnsingh, 1983). We collected only those scats that were deposited in the middle of trails and were either in an aggregation or clustered over 1-1.5 $\mathrm{m}$ along a trail. All scats of each aggregation were collected as a group. We excluded all scats found singly, to avoid confusion with scats of red fox Vulpes vulpes in the subalpine zone and jackal Canis aureus in the temperate zone. Scats were collected during the sign surveys. The location, date and other data such as the occurrence of tracks around scats were also recorded.

A reference key was developed for the identification of prey species on the basis of hair structure and morphology. All scat samples were sun-dried in the field and later ovendried at $60^{\circ} \mathrm{C}$ (Sankar \& Johnsingh, 2002) for $48 \mathrm{~h}$ and preserved in tagged paper bags for later analysis. Each scat was broken, soaked and washed with running water, using fine-mesh (1.0 and $0.5 \mathrm{~mm}$ ) filters (Juarez \& Filho, 2002), to separate prey remains such as hair, bones, hooves, teeth, feathers, nails and other undigested remains. Washed samples of hairs from the scats were dehydrated in absolute alcohol for 12 hours and then placed in xylene for 15-20 minutes (Koppikar \& Sabnis, 1976). Hairs were then slidemounted and examined at $10 \times$ and $40 \times$ magnification. At least 20 hairs were examined from each scat (Mukherjee et al., 1994) and prey species were identified by comparison with the reference collection, using features such as colour, length, thickness, characteristic medullar configurations (Koppikar \& Sabnis, 1976; Reynolds \& Aebischer, 1991; Mukherjee et al., 1994) and cortex-to-medulla ratio. 

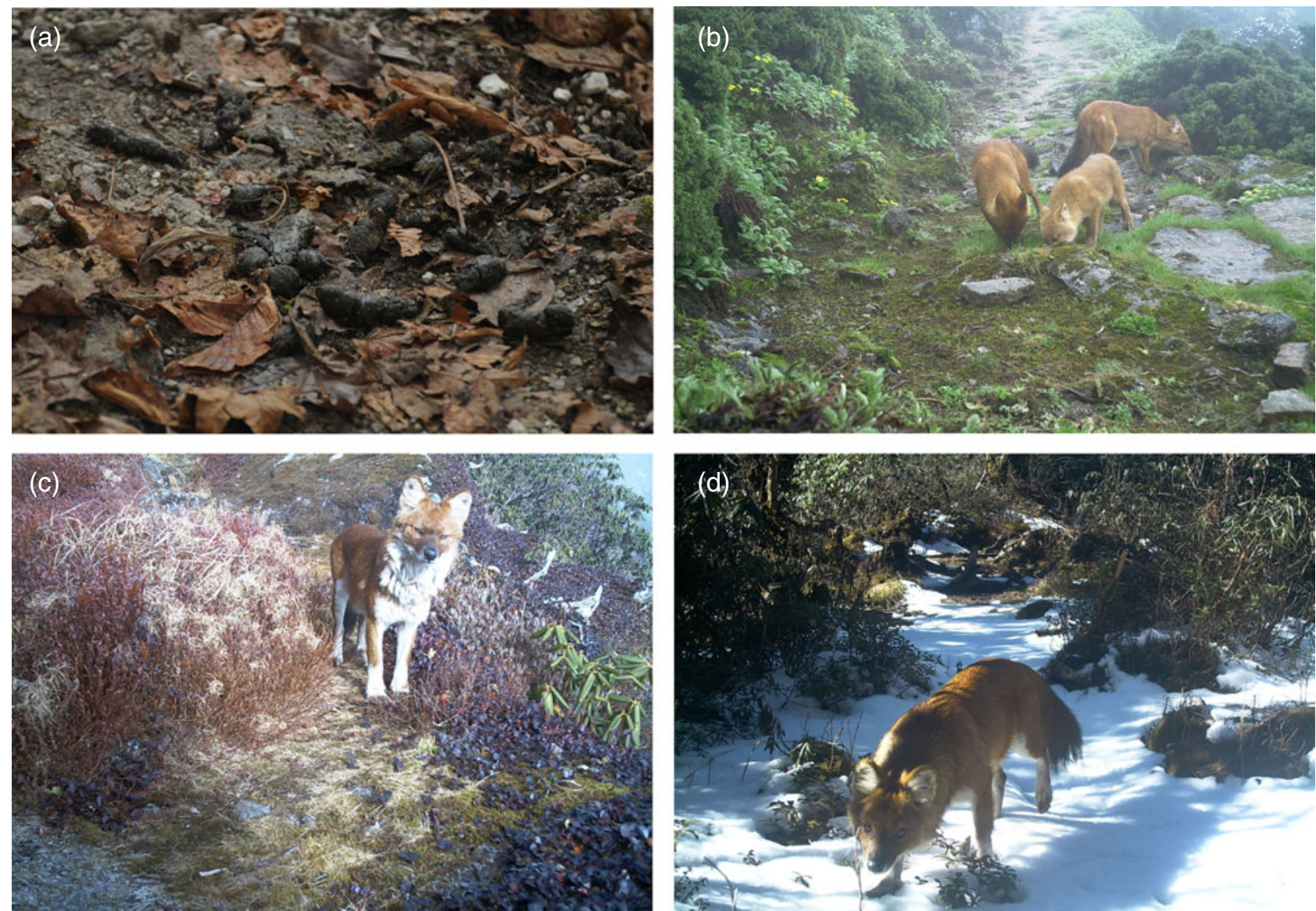

Plate 1 (a) Dhole Cuon alpinus scats found in a cluster in the middle of a trail in temperate forest in the Prek Chu catchment in Khangchendzonga Biosphere Reserve (Figs 1-2). (b) Dhole pack, with one subadult (in the foreground). (c) Adult individual in subalpine-alpine edge forest. (d) Adult in subalpine forest.

\section{Status, distribution and activity}

To estimate the relative abundance of the dhole we calculated the photographic and photo-capture rates. The former is the number of camera days required to capture one independent photographic event of a dhole summed across all camera traps in the study (Carbone et al., 2001). The latter is the number of independent photographic events of dholes divided by the number of trap-days per site. As the camera traps were set in four-picture burst mode we looked at the revisit rate of the known individuals/groups and found that 54 minutes was the maximum time between revisits in a day. Based on this, we considered any capture $>54$ minutes apart as an independent event for calculating photographic and photo-capture rates. Mean photo-capture rates were calculated for all of Prek Chu and for the three survey zones separately (Carbone et al., 2001). The number of camera-trap days was calculated from the date of deployment to the date of retrieval (if the memory card was not full) or to the date of the final photograph. Time of day of the photographs was used to determine the daily activity pattern (Pei, 1998) of the dhole. A daily activity index was calculated as the number of photographs within a 2-hour duration $\times 100 /$ total number of photographs. We also calculated the encounter rate of signs per $\mathrm{km}$ in each survey zone and used the Mann-Whitney $U$ test to test for differences between zones.

\section{Food habit analysis}

Frequency of occurrence $(F)$ of mammalian prey in scats was calculated as $F=n / N$, where $n$ is the number of dhole scats having that particular species and $N$ is the total number of dhole scats analysed (Karanth \& Sunquist, 1995). We subjected the results of the scat analysis to resampling using the bootstrap method, with Simstat (Peladeau, 2000). Subsamples equalling the original sample size of scats were iterated 10,000 times, to generate means and bias-corrected $95 \%$ confidence intervals for percentage frequency of prey items in scats (Mukherjee et al., 2004). The frequency of occurrence of prey species in the scats was converted to relative biomass (Karanth \& Sunquist, 1995) as this provides the best approximation of actual diet (Klare et al., 2011). We used $Y=0.035+0.020 X$ (Floyd et al. 1978), where $Y$ is $\mathrm{kg}$ of prey consumed per scat and $X$ is the mean 
TABLE 1 Details of photographs of the dhole Cuon alpinus captured at six camera-trap sites in the Prek Chu watershed of Khangchendzonga Biosphere Reserve (Figs 1-2) during 2009-2010.

\begin{tabular}{|c|c|c|c|c|c|c|}
\hline Site & Altitude (m) & Habitat & Total trap-days & No. of photographs & Group size & Group composition \\
\hline Ghunsa & 3,100 & Subalpine & 281 & 5 & 4 & Adult \\
\hline \multirow[t]{2}{*}{ Chongrigang } & 4,100 & Alpine & 178 & 12 & 4 & Adult +1 subadult \\
\hline & & & & 3 & 1 & Subadult \\
\hline Kockchurong & 3,700 & Subalpine & 71 & 5 & 5 & Adult \\
\hline Phedi top & 3,900 & Subalpine & 135 & 3 & 1 & Adult \\
\hline \multirow[t]{2}{*}{ Phedhi } & 3,700 & Subalpine & 271 & 5 & 1 & Adult \\
\hline & & & & 5 & 1 & Adult \\
\hline \multirow[t]{2}{*}{ Kasturi top } & 3,300 & Subalpine & 293 & 10 & 1 & Adult \\
\hline & & & & 13 & 1 & Adult \\
\hline
\end{tabular}

weight of an individual of a particular prey type (Ackerman et al., 1984). Multiplying each $Y$ by the number of scats found to contain a particular prey species gave the relative weight of each prey type consumed. These values were used to estimate the percentage biomass contribution of each prey species in the dhole's diet (Klare et al., 2011).

\section{Results}

A sampling effort of 6,278 camera-days across 71 sample sites was achieved in the three survey zones $(1,407,3,061$ and 1,810 camera-days in the temperate, subalpine and alpine zones, respectively), resulting in 4,517 photographs (2,668 of wild animals and 1,849 of domestic animals and people). We recorded 42 mammal species (Sathyakumar et al. 2011), of which three were canids ( $n=518$ photographs): the red fox ( $\mathrm{n}=456 ; 152$ photo-capture events), dhole $(\mathrm{n}=61$; nine photo-capture events) and golden jackal $(\mathrm{n}=1$; one photocapture event). Of the 61 dhole photographs, obtained at six camera-trap sites, 22 contained more than one individual (Table 1). Based on a wide-angle photograph depicting one stationary animal investigating the camera trap and four resting on the ground, pack size was probably no more than five. Subadult individuals (Plate $1 \mathrm{~b}$ ) were photo-captured twice, once with a pack and once alone (Table 1). Thirtynine photographs of the dhole were of a single individual (Table 1). All dhole photo-captures were during daytime, with a peak ( $45 \%$ of the captures) at $08.00-10.00$.

All the adult dholes photographed had a long reddish brown coat and a dark bushy tail, and the pinnae were white inside and reddish brown on the outer side. The muzzle was blackish and relatively short and slightly convex in profile. The nose was black and short white whiskers were present over the white upper and lower lips (Plate 1c). The dorsal and lateral pelage was reddish brown with a yellowish tinge and darker at the neck (Plate 1d). The fore neck, chest and underside were white, with long and dense white fur on the upper chest and throat. Long fur, either white or reddish brown, was present on each paw of adult individuals (Plate 1c,d).
The photographic rate (i.e. the minimum number of days required to capture one dhole photographic event) was 541 days. The overall mean photo-capture rate was $0.12 \pm$ SE 0.05 per 100 days and was highest ( $0.26 \pm$ SE 0.10 per 100 days) in the subalpine zone. Dhole photographs were obtained at five sites (seven photo-capture events) in subalpine forests at elevations of $3,100-3,900 \mathrm{~m}$ and at one site (two photocapture events) at 4,100 $\mathrm{m}$ in the alpine zone (Table 1). The sites were dominated by Abies-Betula-Rhododendron forest or dwarf Rhododendron and Juniperus above 3,700 m.

Whilst walking trails we did not encounter dholes and the only signs we found were 41 scats. The encounter rate of scats was significantly higher $(\mathrm{P}=0.03$, Mann-Whitney $U$ test $)$ in the subalpine (0.21 \pm SE 0.1 scats km ${ }^{-1}, 31$ scats) than in the temperate zone $\left(0.02 \pm \mathrm{SE} 0.01\right.$ scats $\mathrm{km}^{-1}, 10$ scats). We did not detect any evidence of canids in the lower temperate zone (1,850-2,500 m), although we made frequent sightings of jackal below 1,850 m.

Only $29.3 \%$ of dhole scats in a group had more than one prey item. Undigested matter was present in the following decreasing order: hair $(100 \%$, present in all scats), bone (80.5\%), nail (24.4\%), teeth (24.4\%), hoof (7.3\%) and undigested remains of grass (7.3\%). Unidentified rodents were the most frequently found prey item, followed by the serow Nemorhaedus sumatraensis, Himalayan tahr Hemitragus jemlahicus, goral Nemorhaedus goral and pika Ochotona sp., unidentified remains and vegetable matter (Table 2). Serow was the largest prey (mean adult body weight 91-100 kg) consumed, followed by the Himalayan tahr $(80 \mathrm{~kg})$ and goral (30 kg; Prater, 1971). The estimated relative biomass of prey and the relative number of individual prey are also presented in Table 2. The biomass estimates indicate that although dholes killed more pikas and rodents, ungulate prey species (serow, Himalayan tahr and goral) contributed $98.7 \%$ of the total biomass consumed.

\section{Discussion}

The reddish-brown long coat and long white or reddish brown hairs on the paws indicate that the dhole population 
TABLE 2 Diet of the dhole in Khangchendzonga Biosphere Reserve (Fig. 1) as indicated by analysis of 41 scats, with the mean percentage frequency of prey items (with 95\% confidence intervals, CI, from bootstrapping), estimated \% relative biomass of prey, and relative number of individual prey consumed (see text for further details).

\begin{tabular}{llcr}
\hline Prey species & $\begin{array}{l}\text { Mean \% frequency } \\
(95 \% \text { CI })\end{array}$ & $\begin{array}{l}\text { \% relative } \\
\text { biomass }\end{array}$ & $\begin{array}{l}\text { Relative no. of } \\
\text { individuals consumed }\end{array}$ \\
\hline Unidentified rodents & $32(14-41)$ & 1.18 & 57.89 \\
Serow Nemorhaedus sumatraensis & $27(15-41)$ & 52.05 & 5.23 \\
Himalayan tahr Hemitragus jemlahicus & $22(10-34)$ & 34.21 & 4.29 \\
Goral Nemorhaedus goral & $20(7-32)$ & 11.81 & 3.95 \\
Pika Ochotona sp. & $20(10-34)$ & 0.75 & 28.64 \\
Unidentified & $10(2-19)$ & & \\
Vegetable matter & $7(0-15)$ & & \\
\hline
\end{tabular}

TABLE 3 Number of days required to obtain one camera-trap photograph of the dhole (the photographic rate) in Khangchendzonga Biosphere Reserve (Fig. 1) and in seven other protected areas in south Asia (Datta et al., 2008).

\begin{tabular}{lccl}
\hline Protected area & $\begin{array}{l}\text { No. of } \\
\text { trap days }\end{array}$ & $\begin{array}{l}\text { Photographic } \\
\text { rate (days) }\end{array}$ & Reference \\
\hline Khangchendzonga Biosphere Reserve, India & 6,278 & 541 & This study (2008-2010) \\
Namdapha National Park, north-east India & 1,537 & $0^{*}$ & Datta et al. (2008) \\
Hukawng Valley Tiger Reserve, north Myanmar & 8,836 & 4,418 & Lynam (2003) \\
Hkakaborazi National Park, north Myanmar & 1,238 & 29 & Rao et al. (2005) \\
Taman Negara National Park, Peninsular Malaysia & 14,054 & 878 & Kawanishi \& Sunquist (2004) \\
Nam Et-Phou Louey National Protected Area, Lao & 3,588 & 359 & Johnson et al. (2006) \\
Bukit Barisan Selatan National Park, Indonesia & 24,045 & 6,024 & O’Brien et al. (2003) \\
Phu Kheio Wildlife Sanctuary, Thailand & 1,224 & 111 & Grassman (2003)
\end{tabular}

${ }^{*}$ Datta et al. (2008) did not secure any photographs of the dhole but confirmed its presence through indirect evidence, and Mishra et al., (2006) reported skins of dholes from six valleys at high altitudes in Arunachal Pradesh.

in Khangchendzonga Biosphere Reserve could be the subspecies C. alpinus primaevus (Durbin et al., 2004), which has also been reported at lower and middle altitudes in Bhutan (Johnsingh et al., 2007). The presence of thick white fur on the chest and throat also distinguishes it from the dhole of southern India C. alpinus dukhunensis, which is known to be genetically distinct from C. alpinus primaevus (Iyengar et al., 2005). Iyengar et al. (2005) did not find evidence for the recognition of all 11 subspecies of dhole and showed there is admixture of subspecies over a vast area, and therefore genetic analysis is required to determine the true identity of the dhole of Khangchendzonga Biosphere Reserve.

The photographic rate for the dhole in Khangchendzonga Biosphere Reserve (541 days) lies within the range (296,024 days) of that in seven other camera-trap studies in south Asia (Table 3). Trail surveys in Pakke Tiger Reserve in Arunachal Pradesh, India, resulted in a low encounter rate of dhole signs ( $0.26 \mathrm{~km}^{-1}$; Gopi et al., 2010), similar to our encounter rate $\left(0.21 \mathrm{~km}^{-1}\right)$ in Khangchendzonga Biosphere Reserve. Comparison of our results with those of other studies is only tentative, however, as there were differences in study design and camera-trapping effort. More robust methods such as occupancy-based abundance estimation or non-invasive DNA-based capturerecapture studies are required to elucidate the status of the dhole in Khangchendzonga Biosphere Reserve and elsewhere.

Factors that may influence habitat selection by dholes include the availability of medium to large ungulate prey species, water, the presence of other large carnivore species, human population density and suitability of breeding sites (Durbin et al., 2004). In the subalpine forests, serow and goral were relatively abundant and Himalayan tahr was also present (Bhattacharya et al., 2010). No other large or medium-sized carnivore species has been reported from these subalpine forests except the Asiatic golden cat Pardofelis temminckii (Bashir et al., 2011), which is reported to be sympatric with the dhole in Peninsular Malaysia (Kawanishi \& Sunquist, 2008). Presence of large and medium ungulate prey, absence of large carnivores such as the common leopard Panthera pardus and relatively less anthropogenic pressure may be the reasons for the presence of the dhole primarily in subalpine forests in our study area.

Other studies have also indicated that the dhole is diurnal and obtains most of its dietary biomass from ungulate prey (Johnsingh, 1992; Karanth \& Sunquist, 1995; Venkataraman et al., 1995; Kawanishi \& Sunquist, 2008; Borah et al., 2009; Kumaraguru et al., 2011; Kamler et al., 2012). The presence of pikas and rodent species in the diet of the dhole could be because of its ability to flush out and hunt smaller and 
cryptic prey species (Venkataraman, 1996; Kumaraguru et al., 2011). Although too small for the pack as a whole, such small prey is sufficient for an individual dhole (Kumaraguru et al., 2011). Dholes also occasionally consume grass and other vegetation (Cohen et al., 1978; Johnsingh, 1983; Durbin et al., 2004), which explains the presence of undigested vegetation remains in some scats.

Our results indicate that probably only one subspecies of dhole, C. alpinus primaevus, is present in the subalpine forests of Prek Chu. Iyengar et al., (2005) suggested that this subspecies, reported to be 'very rare' in a survey in the early 1980 s (Johnsingh, 1985), and distinct from C. alpinus dukhunensis, should be accorded a high priority for conservation action. Other catchments in Khangchendzonga Biosphere Reserve need to be surveyed, with intensive camera trapping, for the dhole. In Bhutan dholes have caused livestock loss because villagers allowed their livestock to graze unsupervised (Johnsingh et al., 2007). We recommend that livestock depredation cases should be monitored in Khangchendzonga Biosphere Reserve as unsupervised grazing is also practised in this area. Our findings have been shared with the relevant State and Central authorities, for enhancement of the conservation management of the dhole in this region, and a further project has now been initiated to monitor the dhole population in Prek Chu and other catchments in Khangchendzonga Biosphere Reserve.

\section{Acknowledgements}

We are grateful to the Department of Forests, Environment and Wildlife Management, Government of Sikkim, for granting us permission to work in the state. We thank the Wildlife Institute of India, Dehradun, for providing grants and support, and two anonymous reviewers for their valuable comments.

\section{References}

Ackerman, B.B., Lindzey, F.G. \& Hemker, T.P. (1984) Cougar food habits in Southern Utah. Journal of Wildlife Management, $48,147-155$.

Bashir, T., Bhattacharya, T., Poudyal, K. \& Sathyakumar, S. (2011) Notable observations on the melanistic Asiatic Golden cat (Pardofelis temminckii) of Sikkim, India. NeBIO, 2, 1-4.

Bhattacharya, T., Bashir, T., Poudyal, K., Sathyakumar, S., Bisht, S. \& SAHA, G.K. (2010) Distribution, relative abundance and habitat use by mountain ungulates in Prek Chu catchment, Khangchendzonga Biosphere Reserve, Sikkim, India. Galemys, 22, 149-170.

BLANFORD, W.T. (1888-91). The Fauna of British India, Including Ceylon and Burma. Mammalia. Taylor and Francis, London, UK.

Borah, J., Deka, K., Dookia, S. \& Gupta, R.P. (2009) Food habits of dholes (Cuon alpinus) in Satpura Tiger Reserve, Madhya Pradesh, India. Mammalia, 73, 85-88.

Carbone, C., Christie, S., Conforti, K., Coulson, T., Franklin, N., GinsberG, J.R. et al. (2001) The use of photographic rates to estimate densities of tigers and other cryptic mammals. Animal Conservation, 4, 75-79.

Cohen, J.A., Fox, M.W., Johnsingh, A.J.T. \& Barnett, B. D. (1978) Food habits of the dhole in south India. Journal of Wildlife Management, 42, 933-936.

Datta, A., Anand, M.O. \& Naniwadekar, R. (2008) Empty forests: large carnivore and prey abundance in Namdapha National Park, north-east India. Biological Conservation, 141, 1429-1435.

DAVIDAR, E.R.C. (1975) Ecology and behaviour of the dhole or Indian wild dog Cuon alpinus (Pallas, 1811). In The Wild Canids (ed. M.W. Fox), pp. 109-119. Van Nostrand Reinhold, New York, USA.

Durbin, L.S., Hedges, S., Duckworth, J.W., Tyson, M., Iyengar, A. \& Venkataraman, A. (2008) Cuon alpinus. In IUCN Red List of Threatened Species v. 2013.1. Http://www.iucnredlist.org [accessed 16 July 2013].

Durbin, L.S., Venkataraman, A., Hedges, S. \& Duckworth, J.W. (2004) Dhole (Cuon alpinus). In Status Survey and Conservation Action Plan. Canids: Foxes, Wolves, Jackals and Dogs (eds C. Sillero-Zubiri, M. Hoffman \& D.W. Macdonald), pp. 210-219. IUCN, Gland, Switzerland, and Cambridge, UK.

Floyd, T.J., MeCh, L.D. \& Jordan, P.J. (1978) Relating wolf scat contents to prey consumed. Journal of Wildlife Management, $42,528-532$.

Gammie, J. (1894) Mammals. In The Gazetteer of Sikhim (ed. H.H. Risley), pp. 235-240. The Bengal Secretariat Press, Calcutta, India.

Gopi, G.V., Lyngdoh, S. \& Selvan, K.M. (2010) Conserving the Asiatic Wild Dog Cuon alpinus in Western Arunachal Pradesh: Fostering Better Coexistence for Conservation. Final Technical Report Submitted to Rufford Small Grant Programme, London, UK.

Grassman, Jr, L.I. (2003) Thailand Cat Project. Unpublished final report, submitted to Cat Action Treasury, Thailand.

Iyengar, A., Babu, V.N., Hedges, S., Venkataraman, A.B., MacLean, N. \& Morin, P.A. (2005) Phylogeography, genetic structure, and diversity in the dhole (Cuon alpinus). Molecular Ecology, 14, 2281-2297.

JERdon, T.C. (1874) The Mammals of India: Natural History. John Wheldon, London, UK.

Johnsingh, A.J.T. (1983) Large mammal prey-predators in Bandipur. Journal of Bombay Natural History Society, 80, 1-57.

Johnsingh, A.J.T. (1985) Distribution and status of dhole Cuon alpinus Pallas, 1811 in South Asia. Mammalia, 49, 203-208.

Johnsingh, A.J.T. (1992) Prey selection in three large sympatric carnivores in Bandipur. Mammalia, 56, 517-526.

Johnsingh, A.J.T., Yonten, D. \& WangChuck, S. (2007) Livestock-dhole conflict in western Bhutan. Journal of Bombay Natural History Society, 104, 201-202.

Johnson, A., Vongkhamheng, C., Hedemark, M. \& SAITHONGDAM, T. (2006) Effects of human-carnivore conflict on tiger (Panthera tigris) and prey populations in Lao PDR. Animal Conservation, 9, 421-430.

JuAReZ, K.M. \& Filho, J.M. (2002) Diet, habitat use and home ranges of sympatric canids in central Brazil. Journal of Mammalogy, 83, 925-933.

Kamler, J.F., Johnson, A., Vongkhamheng, C. \& Bousa, A. (2012) The diet, prey selection, and activity of dholes (Cuon alpinus) in northern Laos. Journal of Mammalogy, 93, 627-633.

Karanth, K.U. \& Sunquist, M.E. (1995) Prey selection by tiger, leopard and dhole in tropical forests. Journal of Animal Ecology, 64, 439-450.

KaWANishi, K. \& Sunquist, M.E. (2004) Conservation status of tigers in a primary rainforest of Malaysia. Biological Conservation, 120, $329-344$. 
Kawanishi, K. \& Sunquist, M.E. (2008) Food habits and activity patterns of the Asiatic golden cat (Catopuma temminckii) and dhole (Cuon alpinus) in a primary rainforest of Peninsular Malaysia. Mammal Study, 33, 173-177.

Klare, U., Kamler, J.F. \& Macdonald, D.W. (2011) A comparison and critique of different scat analysis methods for determining carnivore diet. Mammal Review, 41, 294-312.

KopPIKAR, B.R. \& SABNis, J.H. (1976) Identification of hairs of some Indian mammals. Journal of Bombay Natural History Society, 73, 5-20.

Kumaraguru, A., Saravanamuthu, R., Brinda, K. \& Asokan, S. (2011) Prey preference of large carnivores in Anamalai Tiger Reserve, India. European Journal of Wildlife Research, 57, 627-637.

Lynam, A. (2003) A National Tiger Action Plan for the Union of Myanmar. Unpublished Report. Myanmar \& Wildlife Conservation Society-International Program, Myanmar Forest Department, Ministry of Forestry, Myanmar.

Mackenzie, D.I. \& Royle, A. (2005) Designing occupancy studies: general advice and allocating survey effort. Journal of Applied Ecology, 42, 1105-1114.

Mishra, C., Madhusudan, M.D. \& Datta, A. (2006) Mammals of the high altitudes of western Arunachal Pradesh, Eastern Himalaya: an assessment of threats and conservation needs. Oryx, 40, 29-35.

Mukherjee, S., Goyal, S.P. \& Chellam, R. (1994) Standardization of scat analysis techniques for leopards (Panthera pardus) in Gir National Park, Western India. Mammalia, 58, 139-143.

Mukherjee, S., Goyal, S.P., Johnsingh, A.J.T. \& Pitman, M.R.P.L. (2004) The importance of rodents in the diet of jungle cat (Felis chaus), caracal (Caracal caracal) and golden jackal (Canis aureus) in Sariska Tiger Reserve, Rajasthan, India. Journal of Zoology, 262, 405-411.

Myers, N., Mittermeier, R.A., Mittermeier, C.G., Da FonseCA, G.A.B. \& Kent, J. (2000) Biodiversity hotspots for conservation priorities. Nature, 40, 853-858.

O’Brien, T.G., Kinnaird, M.F. \& Wibisono, H.T. (2003) Crouching tigers, hidden prey: Sumatran tiger and prey populations in a tropical forest landscape. Animal Conservation, 6, 131-139.

PEI, J.Q. (1998) An evaluation of using auto-trigger cameras to record activity patterns of wild animals. Taiwan Journal of Forest Sciences, $13,317-324$.

Peladeau, N. (2000) Simstat v. 2.o. Provalis Research, Montreal, Canada.

Prater, S.H. (1971) The Book of Indian Animals. Bombay Natural History Society, Oxford University Press, Oxford, UK.
Rao, M., Myint, T., Zaw, T. \& Htun, S. (2005) Hunting patterns in tropical forests adjoining the Hkakaborazi National Park, north Myanmar. Oryx, 39, 292-300.

Reynolds, J.C. \& Aebischer, N.J. (1991) Comparison and quantification of carnivore diet by faecal analysis: a critique, with recommendations, based on a study of the Fox Vulpes vulpes.

Mammal Review, 21, 97-122.

SANKAR, K. \& Johnsingh, A.J.T. (2002) Food habits of tiger (Panthera tigris) and leopard (Panthera pardus) in Sariska Tiger Reserve, Rajasthan, India, as shown by scat analysis. Mammalia, 66, 285-289.

Sathyakumar, S., Bashir, T., Bhattacharya, T. \& Poudyal, K. (2011) Assessing mammal distribution and abundance in intricate Eastern Himalayan habitats of Khangchendzonga, Sikkim, India. Mammalia, 75, 257-268.

Stewart, P. (1993) Mapping the dhole. Canid News, 1, 18-21.

Stewart, P. (1994) Mapping the dhole update. Canid News, 2, 35-36. TAMBE, S. (2007) Ecology and management of the alpine landscape in the Khangchendzonga National Park, Sikkim Himalaya. PhD thesis. FRI University, Dehradun, India.

Venkataraman, A.B. (1996) The dhole or the Asiatic wild dog. Resonance, 1, 74-79.

Venkataraman, A.B., Arumugum, R. \& Sukumar, R. (1995) The foraging ecology of the dhole (Cuon alpinus) in Mudumalai Sanctuary, Southern India. Journal of Zoology, 237, 543-561.

\section{Biographical sketches}

TAWQIR BASHIR is interested in the ecology and conservation of carnivores in mountain ecosystems, with special reference to predator-prey interactions and reducing carnivore-human conflicts. TAPAJT BHATTACHARYA's interests are the ecology and conservation of mountain ungulates, including their habitats and ungulatehabitat interactions, and community-based conservation. KAMAL Poudyal's interests are the ecology and conservation of the wildlife of the Eastern Himalaya and community participation in conservation. MANJARI ROY'S interests are the ecology and conservation of large carnivores, and mangrove ecosystems. SAMBANDAM SATHYAKUMAR is interested in the ecology and conservation of the wildlife of the Himalaya, where he has been following research interests in mountain ungulates, bears, other large carnivores and Galliformes. $\mathrm{He}$ is a member of the IUCN/Species Survival Commission Caprinae, Bear, Galliformes, and Cultural and Spiritual Values of Protected Areas Specialist Groups. 